\title{
Living-donor single-lobe lung transplantation for primary pulmonary hypertension in a child
}

\author{
Hiroshi Date, MD, ${ }^{a}$ Yoshifumi Sano, MD, ${ }^{a}$ Motoi Aoe, MD, ${ }^{a}$ Hiromi Matsubara, MD, ${ }^{\mathrm{b}}$ Kengo Kusano, MD, \\ Keiji Goto, MD, ${ }^{\mathrm{c}}$ Takeo Tedoriya, MD, ${ }^{\mathrm{d}}$ and Nobuyoshi Shimizu, MD, ${ }^{\mathrm{a}}$ Okayama, Japan
}

$\mathrm{T}$ he use of living lung donors has saved the lives of patients who are too ill to wait on the list for cadaveric donors. ${ }^{1}$ In this procedure, two healthy donors are usually selected. ${ }^{2}$ One donor provides the right lower lobe, and the other provides the left lower lobe. These lobes are implanted in the recipient as the whole right and left lungs. However, finding two healthy living donors is not easy. To our knowledge, this is the first reported case of single-lobe transplantation for primary pulmonary hypertension.

\section{Clinical Summary}

A 10-year-old boy had been well until 6 years old in 1998, when symptoms of dyspnea occurred during exercise. Primary pulmonary hypertension was diagnosed, and oxygen inhalation and various oral medications were initiated. In May 1999, when the patient was 8 years old, clinical deterioration required continuous intravenous infusion of prostacyclin. Despite high-dose prostacyclin therapy $\left(90 \mathrm{ng} \cdot \mathrm{kg}^{-1} \cdot \mathrm{min}^{-1}\right.$ ), the patient remained in New York Heart Association functional class III and was unable to go to school. Right heart catheterization revealed highly elevated pulmonary arterial pressure and a reduced cardiac index (Table 1). Preoperative chest radiography demonstrated marked cardiomegaly (Figure 1, A). Two-dimensional echocardiography demonstrated a dilated hypokinetic right ventricle in association with an enlarged right atrium and pulmonary artery, with massive tricuspid regurgitation. Left ventricular function was normal apart from flattening of the interventricular septum (Figure 2, A).

The patient qualified as a candidate for lung transplantation and was registered in the Japan Organ Transplantation Network on April 10, 2001. However, the only realistic option for this patient was to receive a living-donor lobar lung transplant, because obtaining cadaveric donors is extremely difficult in Japan. The only available living donor for the boy was his mother. The surgical options were discussed with the family, and they were willing to proceed with living-donor single-lobe transplantation, with the understanding that it was still an experimental procedure.

From the Departments of Surgery II, ${ }^{\mathrm{a}}$ Cardiology, ${ }^{\mathrm{b}}$ Anesthesiology and Resuscitology, ${ }^{\mathrm{c}}$ and Cardiovascular Surgery, ${ }^{\mathrm{d}}$ Okayama University School of Medicine, Okayama, Japan.

Received for publication Nov 30, 2001; accepted for publication Dec 10, 2001.

Address for reprints: Hiroshi Date, MD, Department of Surgery II, Okayama University School of Medicine, 2-5-1 Shikata-Cho, Okayama 700-8558, Japan (E-mail: hdate@ nigeka2.hospital.okayama-u.ac.jp)

J Thorac Cardiovasc Surg 2002;123:1211-3

Copyright $\odot 2002$ by The American Association for Thoracic Surgery

$0022-5223 / 2002 \$ 35.00+0 \quad \mathbf{1 2 / 5 4 / 1 2 2 1 1 5}$

doi: $10.1067 / \mathrm{mtc} .2002 .122115$
On May 14, 2001, the patient underwent living-donor singlelobe transplantation with the right lower lobe from his 38-yearold mother. Heights and weights were $122 \mathrm{~cm}$ and $19.6 \mathrm{~kg}$ for the recipient and $158 \mathrm{~cm}$ and $52.0 \mathrm{~kg}$ for the mother. The patient was placed in the supine position, and a right anterolateral thoracotomy was made at the level of the fourth intercostal space. The costal cartilage of the fourth rib was divided to allow upward mobility of the fourth rib with application of the ribspreading retractor. The sternum was not divided. A right pneumonectomy and a right lower lobe implantation were performed under conditions of cardiopulmonary bypass. The patient was separated from cardiopulmonary bypass easily after a total of 147 minutes. The initial oxygen tension was $132.9 \mathrm{~mm}$ $\mathrm{Hg}$ with the patient breathing $80 \%$ oxygen, and the systolic pulmonary artery pressure was $32.0 \mathrm{~mm} \mathrm{Hg}$ after discontinuation of cardiopulmonary bypass.

During the early postoperative period, the patient was treated with various cardiovascular medications, such as intravenously administered dopamine, dobutamine, prostaglandin $\mathrm{E}_{1}$, and phosphodiesterase III inhibitor and inhaled nitric oxide. Postoperative immunosuppression was a triple-drug therapy consisting of cyclosporine, azathioprine, and prednisone. The patient was extubated on postoperative day 3 but required emergency reintubation on postoperative day 6 because of left native lung edema of unknown cause. A perfusion scan and pulmonary angiography failed to demonstrate any evidence of pulmonary embolism. Transesophageal echocardiography demonstrated that pulmonary venous flow was well maintained bilaterally. The patient was completely weaned from the respirator within 9 days, and his further course was relatively uneventful. He was discharged from the hospital free of symptoms and without supplementary oxygen on postoperative day 43.

The postoperative right heart catheterization at 2 months revealed remarkable improvement in pulmonary hemodynamics (Table 1). Results of arterial blood gas and pulmonary function tests were excellent. A differential ventilation/perfusion scan, performed at 2 months after the operation, demonstrated $83.1 \%$ perfusion to the right lung (compared with $61.8 \%$ before the operation). Chest radiography demonstrated well-expanded grafts without cardiomegaly (Figure 1,B). Echocardiographic changes included decreases in right atrial and ventricular diameters, round left ventricular shape, and minimum tricuspid regurgitation (Figure $2, B)$. The beneficial effects of this single-lobe transplantation were maintained through a 6-month follow-up period (Table 1). Six months after the operation, the patient has returned to normal school life and is able to carry out daily activities.

\section{Discussion}

Living-donor lobar lung transplantation was introduced by Starnes and colleagues ${ }^{1}$ for patients who were thought to be in too critical 


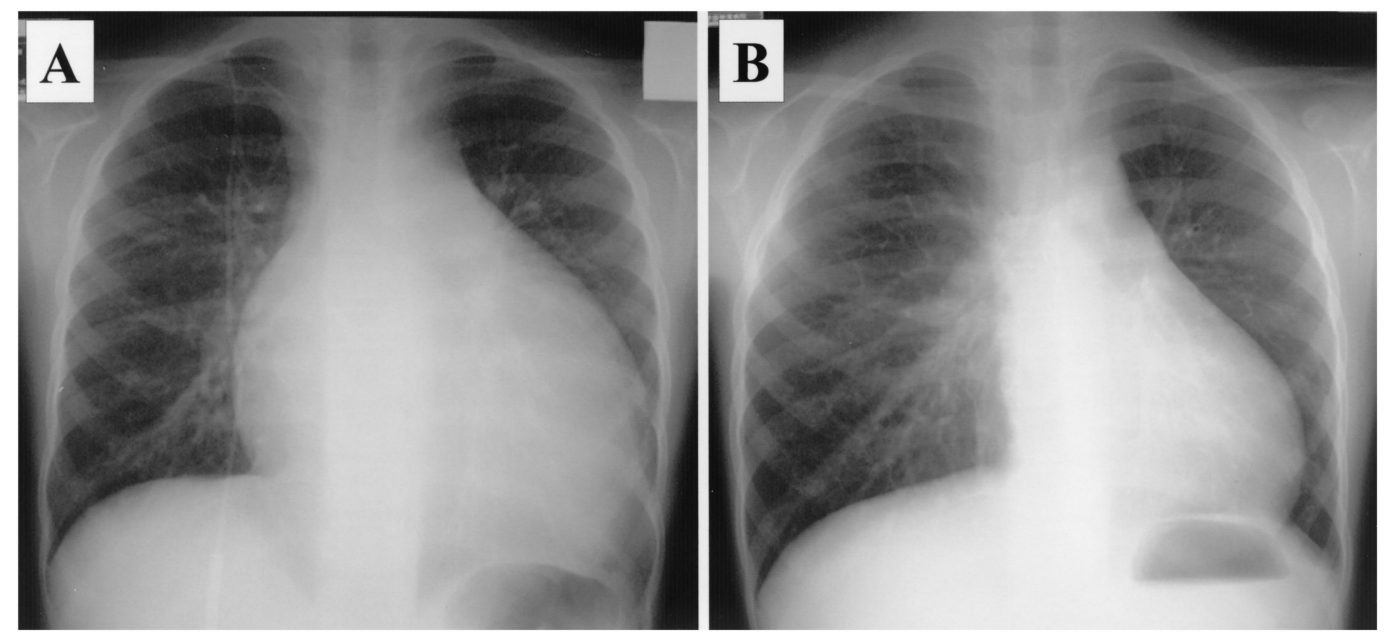

Figure 1. Chest radiography of $\mathbf{1 0}$-year-old boy with primary pulmonary hypertension. A, Before transplantation, marked cardiomegaly is present. B, Two months after receiving right single-lobe transplantation with his mother's right lower lobe, well-expanded lobe fills right chest cavity without cardiomegaly, leaving no detectable dead space.

TABLE 1. Assessment of lung and cardiac function

\begin{tabular}{|c|c|c|c|}
\hline & \multirow[b]{2}{*}{ Pretransplant } & \multicolumn{2}{|c|}{ Posttransplant } \\
\hline & & $2 \mathrm{mo}$ & $6 \mathrm{mo}$ \\
\hline PAP $(\mathrm{mm} \mathrm{Hg})$ & $85 / 40(59)$ & $37 / 15(27)$ & $38 / 12(22)$ \\
\hline PCWP (mm Hg) & 8 & 8 & 10 \\
\hline CVP $(\mathrm{mm} \mathrm{Hg})$ & 9 & -2 & 3 \\
\hline $\mathrm{Cl}\left(\mathrm{L} \cdot \mathrm{min}^{-1} \cdot \mathrm{m}^{-2}\right)$ & 2.7 & 5.0 & 4.3 \\
\hline $\mathrm{PaO}_{2}(\mathrm{~mm} \mathrm{Hg})$ & $139.1\left(0_{2} 2 \mathrm{~L} / \mathrm{min}\right)$ & 94.0 (room air) & 99.7 (room air) \\
\hline $\mathrm{PaCO}_{2}(\mathrm{~mm} \mathrm{Hg})$ & 38.2 & 38.1 & 30.7 \\
\hline $\mathrm{VC}(\mathrm{mL})$ & 1170 & 1350 & 1410 \\
\hline$\%$ VC $(\%)$ & 69.6 & 78.9 & 78.3 \\
\hline $\mathrm{FEV}_{1}(\mathrm{~mL})$ & 1.02 & 1.16 & 1.03 \\
\hline \multicolumn{4}{|l|}{ Ventilation } \\
\hline Right (\%) & 61.1 & 62.2 & 56.9 \\
\hline Left $(\%)$ & 38.9 & 37.8 & 43.1 \\
\hline \multicolumn{4}{|l|}{ Perfusion } \\
\hline Right (\%) & 61.8 & 83.1 & 81.6 \\
\hline Left $(\%)$ & 38.2 & 16.9 & 18.4 \\
\hline
\end{tabular}

$P A P$, Pulmonary artery pressure; $P C W P$, pulmonary capillary wedge pressure; $C V P$, central venous pressure; $C l$, cardiac index; $P a 0_{2}$, arterial oxygen tension; $\mathrm{PaCO}_{2}$, arterial carbon dioxide tension; $V C$, vital capacity; $F E V_{1}$, forced expiratory volume in 1 second.

a condition to wait for a cadaveric lung transplantation. A single donor was used in the beginning, and successful living-donor single-lobe transplantation was reported for a 12-year-old girl with bronchopulmonary dysplasia ${ }^{3}$ and an 11-year-old girl with pulmonary fibrosis after bone marrow transplantation. ${ }^{4}$ However, a 4-year-old child with Eisenmenger syndrome died of massive pulmonary edema related to inadequate microvasculature in the allograft with the persistence of pulmonary hypertension. ${ }^{3}$ Because of this, Starnes and coworkers ${ }^{1}$ developed bilateral living-donor lobar lung transplantation, in which two healthy donors donate their right or left lower lobes.

In Japan the number of available cadaveric donors is quite limited ( $<10$ cases/y), and furthermore brain death is accepted only for those older than 15 years old. It was therefore clear that the only realistic option for this boy was to receive a living-donor lobar lung transplant. Currently our institutional review board protocol at Okayama University School of Medicine states that a spouse or a relative within the second degree are the only donors that can be used for living-donor lobar lung transplantation. The patient's father was not considered a suitable donor because of blood type incompatibility, leaving his mother as the only suitable donor.

The mother's forced vital capacity was $3350 \mathrm{~mL}$. Because the right lower lobe comprises 5 of the 19 lung segments, the forced vital capacity of the graft was estimated to be $882 \mathrm{~mL}(3350 \mathrm{~mL} \times$ $5 / 19$ ), or $52.3 \%$ of the recipient's predicted forced vital capacity 


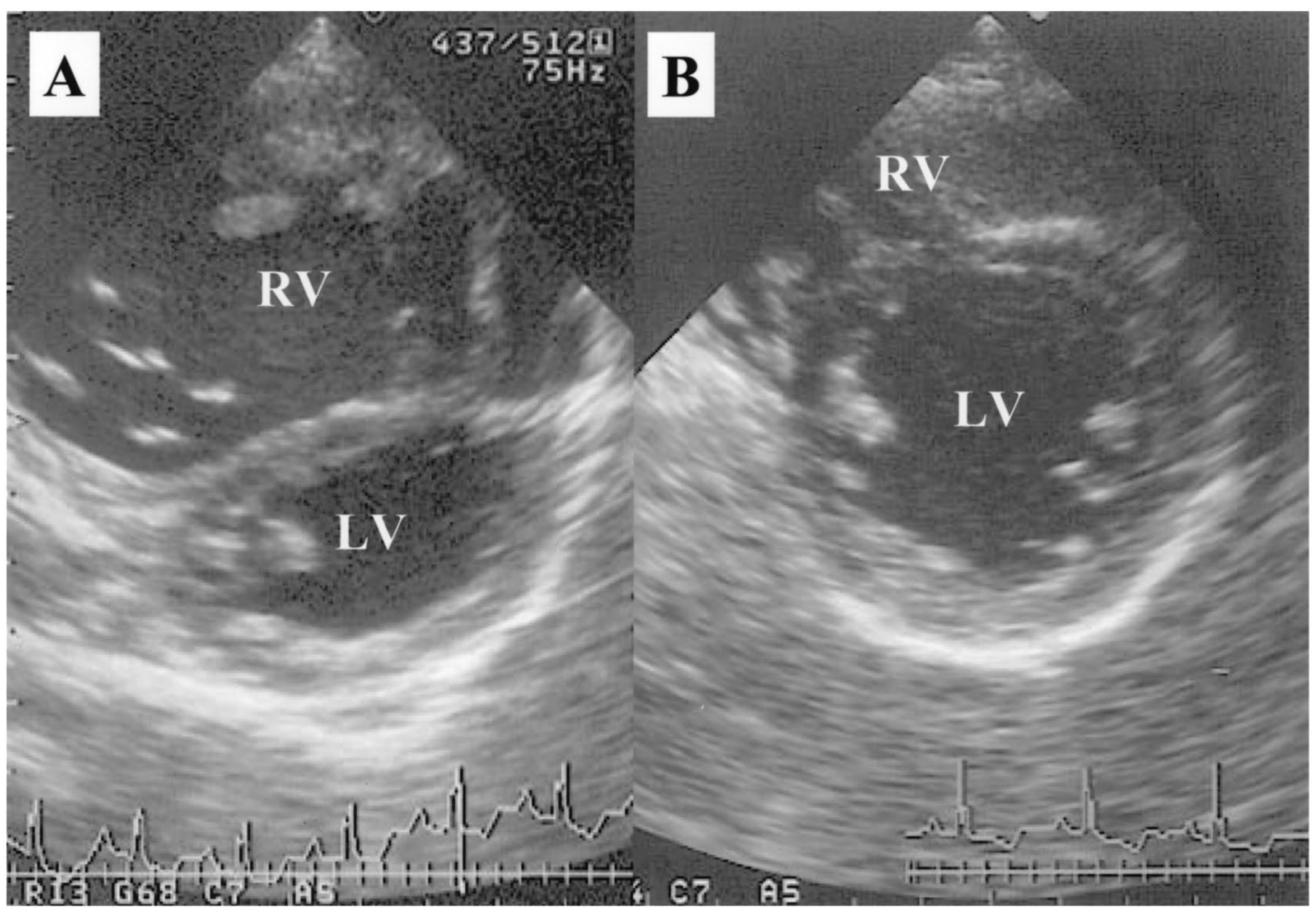

Figure 2. Echocardiographic images before and after single-lobe transplantation. A, Before transplantation, dilated hypokinetic right ventricle (RV) and D-shaped left ventricle (LV) are demonstrated. B, Two months after transplantation, note marked decrease in right ventricular diameter and round left ventricle.

(1685 mL). We considered $52.3 \%$ to be within an acceptable range, because single-lung transplantation had previously been performed successfully for patients with primary pulmonary hypertension. 5

There were obvious concerns regarding whether pulmonary edema would develop in the transplanted single lobe because a preponderance of pulmonary flow would be directed to the transplanted single lobe as a result of high pulmonary vascular resistance in the remaining native lung. Pulmonary arterial pressure became nearly normal immediately after transplantation, and pulmonary edema did not occur in the transplanted lobe even though it received more than $80 \%$ of the cardiac output.

These findings validated the functional capacity of a single lobe to handle the cardiac output of a recipient with primary pulmonary hypertension when the size matching is adequate. However, longterm durability of these hemodynamics as the boy grows remains a major unresolved issue.

\section{References}

1. Starnes VA, Barr ML, Cohen RG, Hagen JA, Wells WJ, Horn MV, et al. Living-donor lobar lung transplantation experience: intermediate results. J Thorac Cardiovasc Surg. 1996;112:1284-91.

2. Cohen RG, Barr ML, Schenkel FA, DeMeester TR, Wells WJ, Starnes VA. Living-related donor lobectomy for bilateral lobar transplantation in patients with cystic fibrosis. Ann Thorac Surg. 1994;57:1423-8.

3. Starnes VA, Barr ML, Cohen RG. Lobar transplantation: indications, technique, and outcome. J Thorac Cardiovasc Surg. 1994;108:403-11.

4. Svendsen UG, Aggestrup S, Heilmann C, Jacobsen N, Koch C, Larsen $\mathrm{B}$, et al. Transplantation of a lobe of lung from mother to child following previous transplantation with maternal bone marrow. Eur Respir J. 1995;8:334-7.

5. Pasque MK, Trulock EP, Cooper JD, Triantafillou AN, Huddleston $\mathrm{CB}$, Rosenbloom M, et al. Single lung transplantation for pulmonary hypertension: single institution experience in 34 patients. Circulation 1995;92:2252-8. 